\title{
Experimental Study of a Solar Adsorption Refrigeration Unit, Factorial Analysis
}

\author{
Ghassan M. Tashtoush", Bourhan M. Tashtoush, Mustafa M. Jaradat \\ Mechanical Engineering Department, Jordan University of Science and Technology, Irbid, Jordan \\ Email: gtash@just.edu.jo
}

Received November $14^{\text {th }}, 2011$; revised April 28 $8^{\text {th }}, 2012$; accepted May $4^{\text {th }}, 2012$

\begin{abstract}
An experimental study was performed on an adsorption refrigeration unit powered by a solar energy and equipped with three different types of activated carbon (1: Coconut, 2: Palm seeds, 3: Charcoal). In this Study design, factorial analysis and optimization of a prototype unit were described. The activated carbon coupled with methanol was used as an adsorbent-adsorbate pairs. Experimental tests were carried out on an adsorptive solar-powered refrigerator for the three pairs. The temperatures of the bed of each adsorber and the corresponding refrigerator temperature for both the adsorption and desorption cycles respectively were recorded and studied as a response. Then a factorial analysis was carried out considering the type of activated carbon and the times interval as factors. The results showed that coconut have the highest bed temperature during the day cycle with a mean of $77.5^{\circ} \mathrm{C}$ and the lowest mean temperature during the night cycle with a mean of $12.9^{\circ} \mathrm{C}$. In addition, it was found from the analysis that the coconut shell activated carbon has the highest coefficient of performance of 0.25 .
\end{abstract}

Keywords: Solar Adsorption; Activated Carbon; HVAC, SAR

\section{Introduction}

Solar refrigeration system is more recognized as a priority in developing countries. This is due to the needs for refrigeration, for food as well as for vaccine preservation. The system is perfect for transporting temperature sensitive vaccines and life-saving medical supplies because the portable units will maintain a constant temperature for the vaccines.

The SAR system is one of the most promising technologies because it is environmentally friendly. It has the advantages of zero Ozone Depletion Potential (ODP), and zero Global Warming Potential (GWP) compared to the CFC emissions where it is considered responsible for about one-third of the global greenhouse effect as shown in the environmental impact of fluorocarbon traces in the atmosphere [1]. The interest for adsorption refrigeration or heat pumping is due to the fact that they are environmentally friendly and that they can use low heat source (such as solar energy) as driving force [2-5].

Therefore the SAR cooling system can be considered as possible solution to the emission problem since they operate with water and methanol, which are fully ecologically compatible and non-toxic refrigerant fluids.

In addition to domestic applications, the SAR system

"Corresponding author. is applicable for market demands because:

- The system is easy to operate;

- The system needs low operating cost and maintenance; The system does not contain any noisy components such as compressors and pumps;

- Easy to regulate the capacity of the system.

Adsorbents are materials possess a permanent porous structure that, at low temperatures, acts like a sponge, soaking up or adsorbing the methanol (the refrigerant). As the temperatures elevated, the refrigerant released or desorbed. This adsorption cycle is silent in operation and most suited for remote locations without electricity supply since they can be powered by purely thermal energy like solar energy.

In the SAR system the adsorbent packed in a sealed collector painted black to enhance the solar radiation absorption. The solar energy heats the high concentration of adsorbent and container to the maximum cycle temperature during the day time where the refrigerant starts desorbing from the adsorbent. In the condenser the refrigerant vapor changed to liquid and moves by gravity to the receiver or directly to the evaporator as shown in the schematic diagram in Figure 1. The adsorbent is cooled down to near ambient temperature, during the night cycle, thus reducing the pressure of the entire system. The refrigerant boils in the evaporator and causes heat to be 


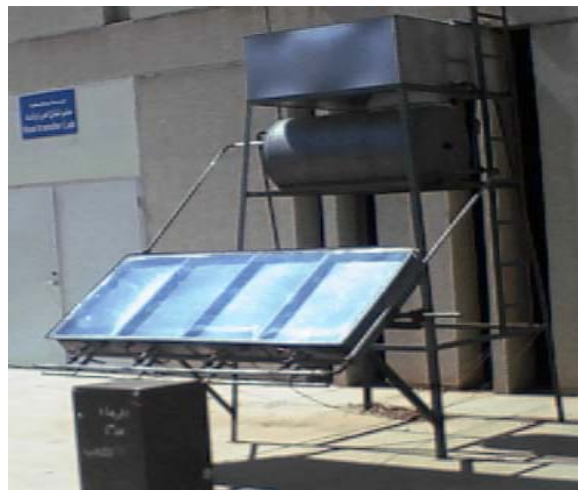

Figure 1. Photograph of the designed prototype.

absorbed from the immediate environment and the adsorbent pressure equals the saturated vapor pressure of the refrigerant, As a result the refrigerant vapor is re-adsorbed into the adsorbent, while cooling effect is produced [2].

Various studies conducted to determine the suitable adsorbent-adsorbate pairs for various applications also to quantify the cooling coefficient of performance (COP) with respect to the operating temperatures [6-11]. The disadvantage of such systems was the low heat transfer coefficient in the adsorbent bed, which influence the thermodynamic efficiency of the SAR system.

Recently a lot of attention has been paid to use adsorption refrigeration systems for both ice-making and air conditioning. For example, activated carbon-methanol is a good working pairs where experimental results have been obtained with a heat source of about $90^{\circ} \mathrm{C}-100^{\circ} \mathrm{C}$ and a specific cooling power of $2.6 \mathrm{~kg}$ ice/day per $\mathrm{kg}$-adsorbent for ice-making and $150 \mathrm{~W} / \mathrm{Kg}$-adsorbent for air conditioning was achieved. More work regarding activated carbon-methanol pairs for ice-making is required, in which $5 \mathrm{Kg}$-ice/day per $\mathrm{Kg}$ adsorbent will be expected.

The adsorption cycle for refrigeration or heat pumping is a succession of two periods: 1) Heating-desorption-condensation period at high pressure (saturation pressures of the adsorbate at the temperature of the condenser); 2) cooling-adsorption-evaporation period at low pressure (saturation pressures of the adsorbate at the temperature of the evaporator).

In this research an experimental study of a solar adsorption refrigeration system was performed with three different types of activated carbon as an adsorbents paired with methanol as the adsorbate. Statistical analysis then performed to compare the three different types used and to choose the best one among them.

\section{Designs of Experiments}

In this study, we have an experiment that includes two factors that we think they will be an important part of the way we learn about how the system works. Those factors are:
1) The adsorbent type in three levels:

- Coconut-shells,

- Palm seed,

- Charcoal.

2) The time interval: this factor contains ten levels for each cycle i.e. ten levels for desorption cycle (day cycle), and ten levels for adsorption cycle (night cycle).

The levels of the factors were selected randomly from larger populations of factor levels to insure unbiased results, and we wish to extend our conclusion to the entire population of factor levels. Three types of activated carbon were selected because they can be desorbed or charged by using low-grade thermal energy provided by flat-plate solar collector, which is commercially available in Jordan. Jordan has different climatic regions with a good solar insolation level (mean insolation is $650 \mathrm{~W} / \mathrm{m}^{2}$ ) and the sun rises in most days of the year. For example, Ghor Safi and Aquaba in summer times have solar radiation time exceeding eleven hours and few full cloudy days. For these reasons, Jordan will be a good place to construct solar cooling systems.

The simple adsorption-refrigeration cycle consists of two vessels that are connected to each other's by conduit. The first vessel works as adsorber in the discharging process and as generator in the charging process. The second vessel contains the adsorbate that works as evaporator in the discharging process and as condenser in charging process as shown in Figure 2.

The designed SAR unit shown in Figure 1 consists of the following components:

1) Flat plate collector with three adsorbers.

2) A condenser and evaporator used on the prototype already exist on the absorption refrigerant connected with the refrigerant header. The condenser is supplied with squared steel sheets that act as fins to increase the surface area so that increasing the heat losses from the condensing refrigerant to the environmental medium.

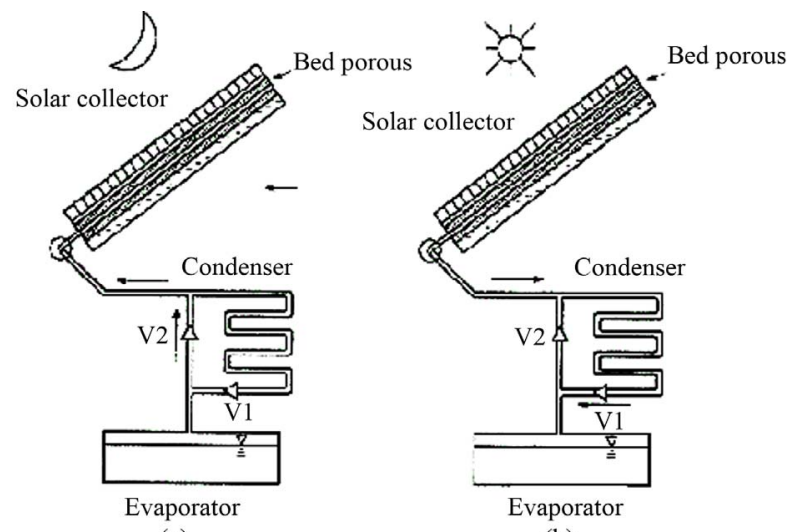

(a)

(b)

Figure 2. Solar Adsorption Refrigeration scheme. (a) Cold production and adsorption stage; (b) Heating and desorption stage [7]. 
3) Storage tanks (Two, $0.5 \mathrm{~m}^{3}$ each), the first one is for hot water storage (this water may be considered as byproduct for domestic applications) while the second one is for tap water that is used to absorb the energy liberated during the adsorption process (during the night cycle).

4) Conduits for fluid transfer, these conduits connect the evaporator with the adsorber and the condenser. Another group of conduits connects the solar system with adsorbers. It is recommended that conduits must not have a large number of elbows and their lengths are as short as possible to decrease pressure drop.

Experimentation was performed on three adsorbents (Activated carbons) contained in the bed. The bed of each adsorber consists of one type of the three activated carbon (coconut shells, palm seed and charcoal), located on fine steel sieves. The activated carbons are of the same grade so that the comparison is made under the same conditions. To acquire the heat that will be released during the adsorption process copper tubes pass through the adsorber. The flat plate collector $\left(1.78 \times 0.78 \mathrm{~m}^{2}\right.$ and $20 \mathrm{~cm}$ thick) is made of steel shells. A grid holds $15 \mathrm{~kg}$ of activated carbon ( $5 \mathrm{~kg}$ for each bed) in the upper shell, which plays the role of solar collector. It is covered by a thin black sheet $(5 \mathrm{~mm})$, and a single glass, the flat plate collector is $40^{\circ}$ tilted to maximize the solar energy collected. A valve opens into a common header connected to each bed such that the operating bed is the one with the opened valve. Each bed was separated from the adjacent with an insulation fiber so that the readings will be individual and more reliable.

A black sheet is placed directly over the activated carbon in order to increases the absorption of the solar radiation. A space separates the black sheet from a glass panel of about $5 \mathrm{~cm} .5 \mathrm{~mm}$ thick glass panel covers each bed to prevent the long wave radiation from escape like a greenhouse effect.

Four thermocouples in this experiment were used to measure the temperature inside the system: three for the beds and located inside the activated carbon and the forth is located inside the refrigerant that is loaded with about $4 \mathrm{~kg}$ of food.

\section{Results and Discussion}

The SAR unit shown in Figure 1 was used to experimentally study the effect of the three adsorbent types (coconut shell, palm seed, and charcoal) on its optimal cooling temperature, thus recommending the most appropriate adsorbent for such systems. The data were taken during the month of June using data harvest in- strument and analyzed statistically with two factors, three levels for the first factor and ten levels for the second factor as described before. Since the levels of the factors are not equal; general full factorial design technique was used. The results for the above setting are discussed in the following.

Figures 3 show the adsorbent temperature using the three adsorbers. Each set of data represents the bed temperature for each activated carbon used as function of time during the day time under the sunny conditions.

It can be seen that coconut shell had the highest bed temperature between the three beds followed by palm seed, where the maximum temperatures for coconut shell, palm seed and charcoal were $108^{\circ} \mathrm{C}, 97^{\circ} \mathrm{C}$ and $92^{\circ} \mathrm{C}$, respectively.

Figure 4 shows the refrigerator temperatures using coconut shell as an adsorber in the bed, in which the minimum temperature reached in the refrigerator was $8{ }^{\circ} \mathrm{C}$ at $27^{\circ} \mathrm{C}$ ambient temperature. The effective refrigeration started at 21:22 and the temperature decreased gradually until it reached $8^{\circ} \mathrm{C}$ at 01:22 next day then it increased.

Using palm seed as an adsorber in the bed, the minimum temperature could be reached was $10^{\circ} \mathrm{C}$ at $02: 51$. The cooling starts at 21:51 until it reached to the minimum temperature and then start to increase.

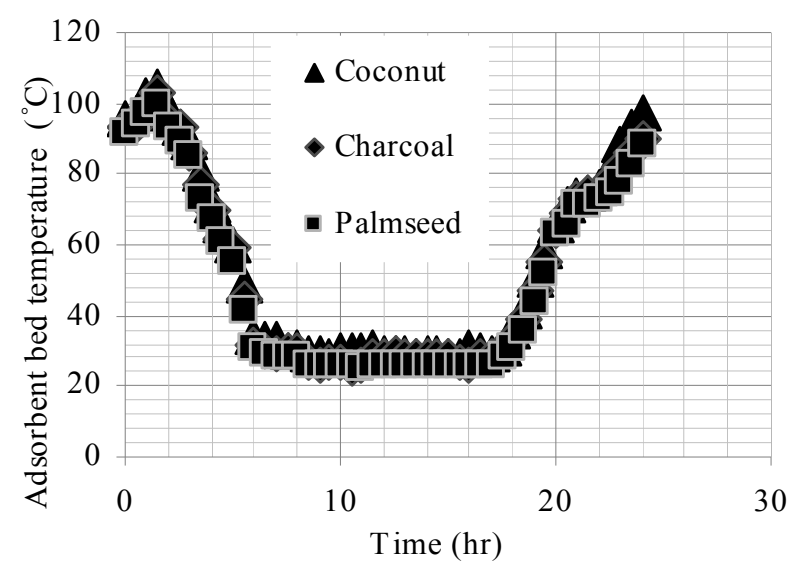

Figure 3. Adsorbent bed temperature using three types of activated carbon.

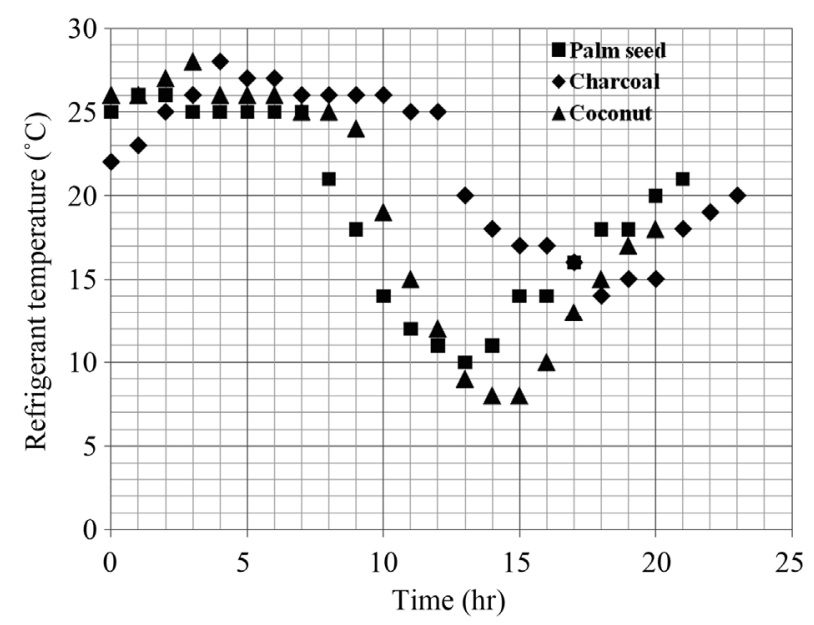

Figure 4. Refrigerant temperatures during the adsorption process for the three activated carbon. 
On the other hand, the cooling starts at 22:31 until it reaches the minimum temperature $14^{\circ} \mathrm{C}$ at $03: 31$ when using charcoal as an adsorber in the bed. Compared to previous two adsorbers, a lag in the cooling starting time is clearly observed. These differences could be explained based on the fact that activated carbons produced from different raw materials may have much different adsorbent qualities. For large adsorption capacity, a large specific surface area is preferable, but the creation of a large internal surface area in a limited volume inevitably gives rise to large numbers of small sized pores between adsorption surfaces. The size of the microspores determines the accessibility of adsorbate molecules to the internal adsorption surface, so the pore size distribution of microspores is another important property for characterizing adsorptivity of adsorbents.

\subsection{Coefficient of Performance (COP) Calculation}

The coefficient of performance, COP, is the ratio of desired result to input which used as an index of performance of a refrigerator or heat pump. This measure of performance may be larger than 1 , and we want the COP to be as large as possible.

In an operating cycle the input is the network into the device and the desired result is the heat supplied at the low temperature so the COP definition is

$$
\mathrm{COP}_{R}=\frac{Q_{L}}{W_{n e t, i n}}
$$

The maximum coefficient of performance for the refrigerator may be calculated as:

$$
\mathrm{COP}_{R}=\frac{Q_{L}}{Q_{H}-Q_{L}}=\frac{Q_{C}}{Q_{g}}=\frac{T_{g}\left(T_{a}-T_{e}\right)}{T_{e}\left(T_{g}-T_{c}\right)}
$$

For the coconut shells activated carbon adsorber

$$
\begin{aligned}
& T_{g}=110^{\circ} \mathrm{C}=383.15 \mathrm{~K} \\
& T_{c}=T_{a}=27^{\circ} \mathrm{C}=300.15 \mathrm{~K} \\
& T_{e}=8^{\circ} \mathrm{C}=281.15 \mathrm{~K}
\end{aligned}
$$

And the maximum coefficient of performance will equal to (0.31). Similarly for the palm seed activated carbon

$$
\begin{aligned}
& T_{g}=101^{\circ} \mathrm{C}=374.15 \mathrm{~K}, \\
& T_{e}=10^{\circ} \mathrm{C}=283.15 \mathrm{~K}, \\
& T_{a}=T_{c}=300.15 \mathrm{~K}
\end{aligned}
$$

The maximum COP will equal to (0.3), and lastly for the charcoal activated carbon we have the following

$$
\begin{aligned}
& T_{g}=92^{\circ} \mathrm{C}=365.15 \mathrm{~K}, \\
& T_{e}=14^{\circ} \mathrm{C}=287.15 \mathrm{~K}, \\
& T_{a}=T_{c}=300.15 \mathrm{~K}
\end{aligned}
$$

temperatures (the maximum COP will equal to (0.25).

In reality the coefficient of performance for such systems ranges from 0.3 to 0.8 (as found in the literature) and this depends on the adsorption pair in use and on the solar collector specification.

\subsection{Statistical Analysis}

Based on the adsorber temperature data (during the day cycle) it was found that there are two factors of interest; the first factor is the adsorber type, which has three levels 1) the coconut shell; 2) the palm seed; 3) and charcoal. The second factor is the time which has ten levels. Each run has two replicates and the data were collected randomly; so that to get unbiased estimation.

The statistical output for the desorption cycles including the fits and the residuals were achieved by using the general full factorial design since the level are not balanced for each factors. These output contains sixty runs resulted from this equation $(a b n=3 \times 10 \times 2=60$ where $a=3$ is the number of levels for the adsorbent type factor, $b=10$ is the number of levels for the time factor, and $n=$ 2 is the number of replicates). The residual describes the error in the fit of model to the $i^{\text {th }}$ observation which is used to check the assumption that the errors were approximately normally distributed with constant variance.

Table 1 represents the analysis of variance for the beds temperature using adjusted sum of square for tests. This table shows the degrees of freedom for each source.

The total degree of freedom (DF) is equal to one less than the total number of runs ( $\mathrm{DF}=60-1=59)$. This table shows the analysis of variance procedure for the solar adsorption refrigeration cycle. From this analysis, the F-value for the adsorbent equal to 13.54 compared to the $\mathrm{F}$ value read from the F-distribution with a level of significance $\alpha=0.05$ as follows;

$$
\begin{aligned}
& f_{\alpha, a-1, a b(n-1)}=f_{0.05,2,30}=4.17 \\
& f_{\alpha, b-1, a b(n-1)}=f_{0.05,9,30}=2.21
\end{aligned}
$$

where both $f$ values are obtained from (Table $V$ : percentage of the F-Distribution, Montgomery) [12]. Since the F-value $>f_{0.05,2,30}=4.17$ and $f_{0.05,9,30}=2.21$, It can be concluded that there is main effects of adsorbent type and the time interval on the temperature of the beds.

Table 1. Analysis of Variance for beds temperature versus adsorbent type; day time, using adjusted SS for tests.

\begin{tabular}{ccccccc}
\hline Source & DF & Seq SS & Adj SS & Adj MS & F & P \\
\hline Adsorbent & 2 & 503.10 & 503.10 & 251.55 & 13.54 & 0.0 \\
$\begin{array}{c}\text { Time } \\
\text { Adsorb- }\end{array}$ & 9 & 24324.75 & 24324.75 & 2702.7 & 145.4 & 0.0 \\
ent*Time & 18 & 83.90 & 83.90 & 4.66 & 0.25 & 0.998 \\
Error & 30 & 557.50 & 557.50 & 18.58 & & \\
Total & 59 & 25469.25 & & & & \\
\hline
\end{tabular}


Furthermore, since $f_{0.05,2,30}=4.17>0.25$, there is no indication of interaction between these two factors as clearly shown in Figure $\mathbf{5}$.

Almost no interaction was shown between the three different adsorbents. While for the time intervals an interaction between the sixth and seventh intervals (13:33 and 14:33) is clearly shown.

Figure 6 shows the residuals versus the order of the data where the response is the beds temperature for desorption cycles. It can be easily seen that the plot does not indicate any serious model inadequacies since the data are uniformly distributed. The normality probability plot of residuals is depicted in Figure 7 showing a little bit tails that do not fall exactly along a straight line passing through the center of the plot.

This indicates some potential problem with the normality assumption. However, no serve deviations or any model adequacy from normality are obvious apparent.

The beds temperature increase during the day as the sun rises until it reaches the peak at the noontime and then it is decreases until the sunset. It is also clear that the activated coconut shell has the highest mean bed temperature of $77.5^{\circ} \mathrm{C}$.

Figure 8 shows the effects plot and the data means for the beds temperature during desorption cycle. It is clearly seen that there is a main effect of the two variables (adsorbent type and time) on the bed temperature response.

Figure 9 shows comparative box plots for the beds temperature data for the three types of adsorbents during the day cycle (desorption). These comparative box plots indicate that the median of the coconut shell was the highest of the three adsorbers followed by the palm seed and the charcoal. The box-and-whisker plot shows the variability of the observations within a treatment (factor level) and the variability between the treatments. The coconuts shell adsorber has a slightly large sample dispersion or variance as shown.

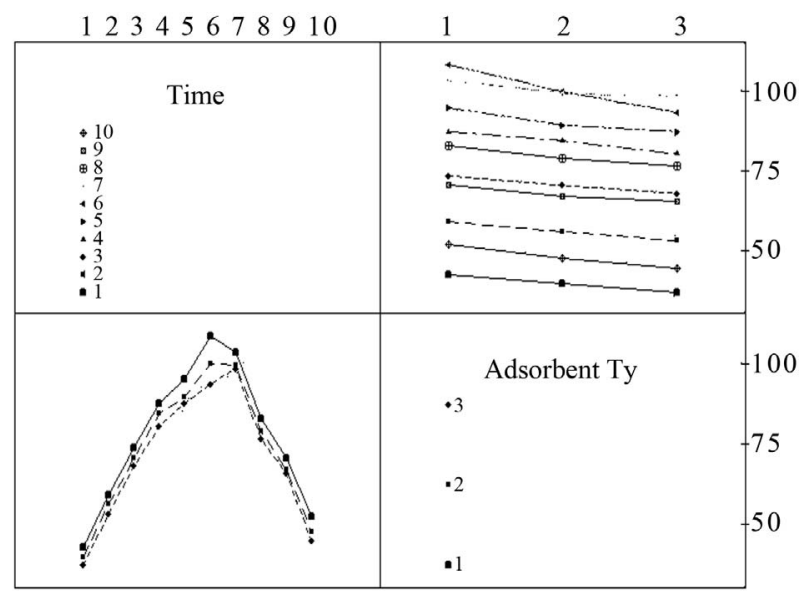

Figure 5. Interaction plot-data means for the beds temperature.

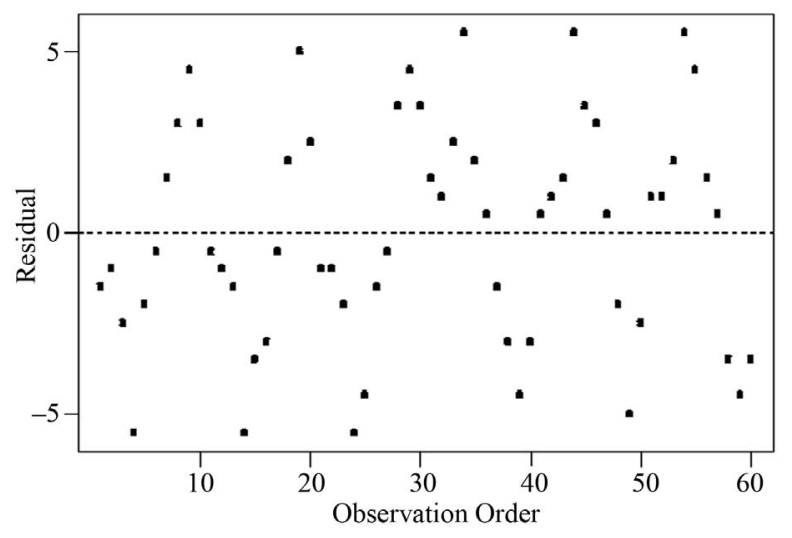

Figure 6. Residual versus the order of data (response is the bed temperature).

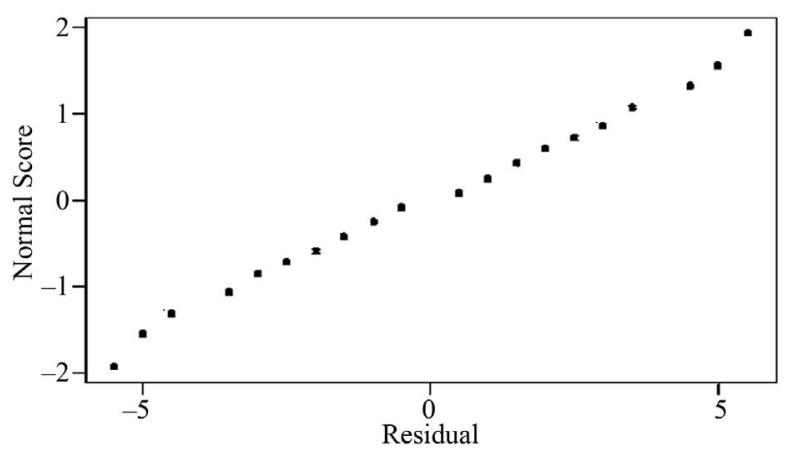

Figure 7. Normal probability plots of the residuals (response is the beds temperature).

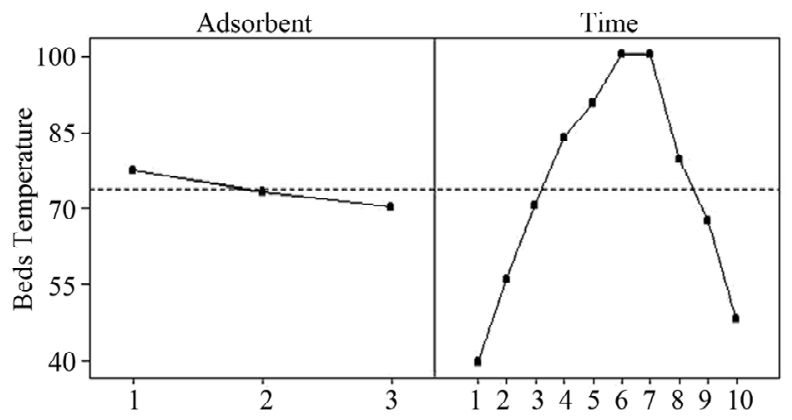

Figure 8. Main effect plot-data means for beds temperature.

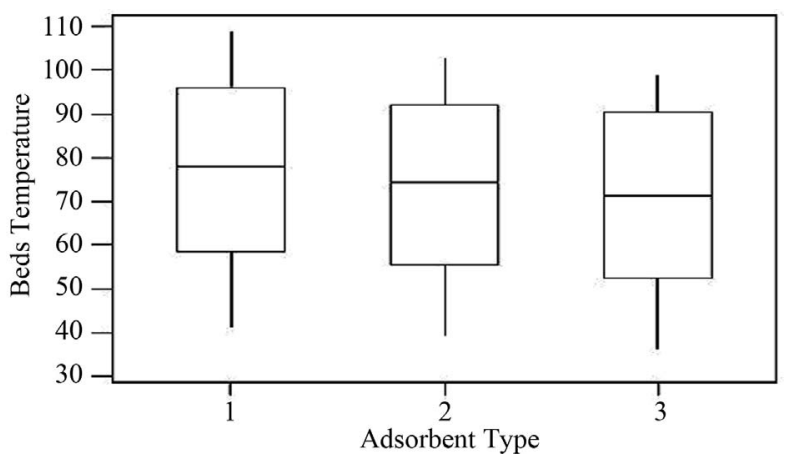

Figure 9. Box-and-whisker plots of beds temperature for the three different adsorbers. 
The analysis of variance for desorption cycle was summarized in Table 2 at level of significance $\alpha$ of 0.05 . From the F-distribution tables;

$$
f_{\alpha, a-1, a b(n-1)}=f_{0.05,2,30}=3.32
$$

and

$$
f_{\alpha, b-1, a b(n-1)}=f_{0.05,9,30}=2.16 \text {. }
$$

Since the $\mathrm{F}$ value $>7.16$, it can be concluded that there is a main effects of adsorbent type and the time on the refrigerator temperature. And since $f_{0.05,2,30}>1.02$ there is no indications of interaction between these factors. Again, the residuals are equal to the collected refrigerator temperatures minus the fitted ones.

Figure 10 shows the effects plot and the data means for the refrigerator temperature during the adsorption cycle. It is seen that there are large main effects of the two factors especially for the first factor (the adsorbent type) on the response. As shown in the figure the coconut shell A.C. has the lowest temperature effect on the refrigerator followed by the palm seed (3) and charcoal (2).

Figure 11 shows the interactions between the variables belong to the adsorption cycle. It is obviously seen that no interactions were obtained. Figure 12 shows a comparative box-and-whisker plot of the refrigerator temperature, during the adsorption cycle, for the three adsorbers.

It is obviously seen the adsorber 1) (coconut shell A.C) has the lowest median of $12.9^{\circ} \mathrm{C}$ followed by adsorber; 2 ) (the palm seed A.C.) with a median of $15.3^{\circ} \mathrm{C}$ and lastly the adsorber; 3) (the charcoal A.C.) with a median of $17.4^{\circ} \mathrm{C}$. In addition, it is shown that the three adsorbers had a large sample variance especially the charcoal adsorber since the whisker from the lower quartile to the minimum value is too small compared to the whisker from the upper quartile to the maximum value. Figure 13 shows the residuals versus the data order during the adsorption cycle, where the response was the refrigerator temperature. It is seen clearly from the figure that there is an inadequacy in the data distribution and there is an inequality of the variance.

The normal probability plot of the residuals, during the adsorption cycle, for the refrigerator temperature as the response is shown in Figure 14. It is clearly seen that

Table 2. Analysis of Variance for refrigerator temperature versus adsorbent type; night time, using adjusted SS for tests.

\begin{tabular}{ccccccc}
\hline Source & DF & Seq SS & Adj SS & Adj MS & F & P \\
\hline Adsorbent & 2 & 202.800 & 202.800 & 101.400 & 41.39 & 0.000 \\
Night time & 9 & 1121.750 & 1121.750 & 124.639 & 50.87 & 0.000 \\
$\quad$ (NT) & & & & & & \\
Adsor*NT & 18 & 45.200 & 45.200 & 2.511 & 1.02 & 0.463 \\
$\quad$ Error & 30 & 73.500 & 73.500 & 2.450 & & \\
$\quad$ Total & 59 & 1443.250 & & & & \\
\hline
\end{tabular}

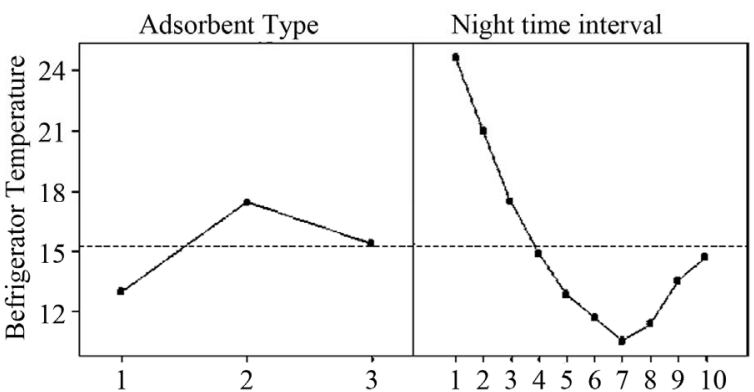

Figure 10. Main effect plot-data means for refrigerator temperature.

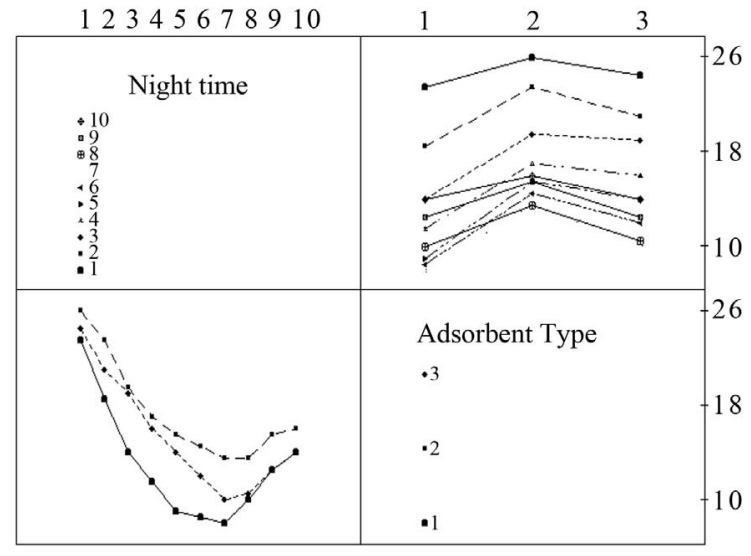

Figure 11. Interaction plot-data means for the refrigerator temperature.

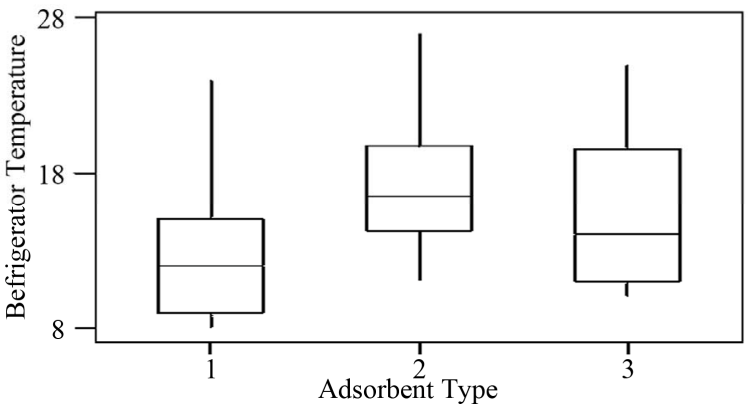

Figure 12. Box-and-whisker plots of the refrigerator temperature for the three different adsorbents.

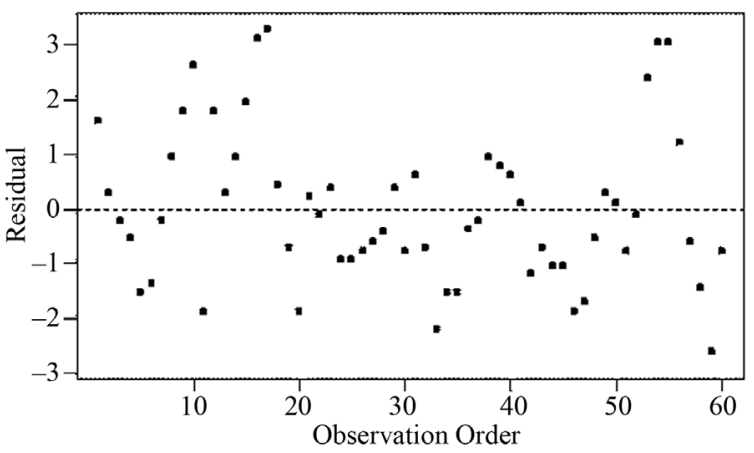

Figure 13. Residuals versus the order of the data (the response is the refrigerator temperature). 


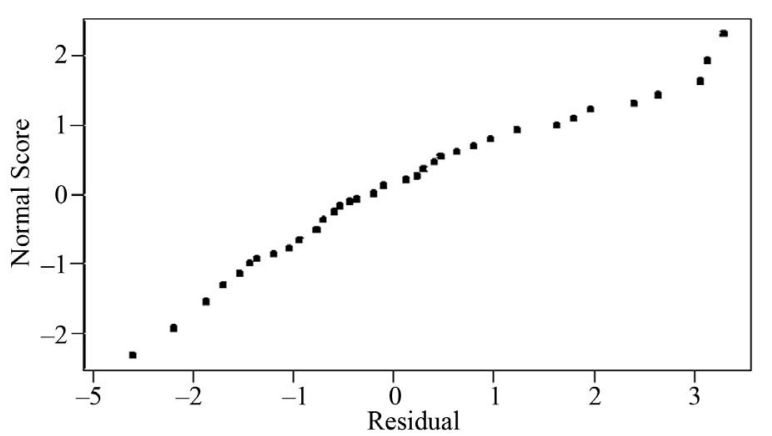

Figure 14. Normal probability plots of the residuals (the response is the refrigeration temperature).

there is no problem with the normality assumption except for the upper tail that do not fall exactly along a straight line passing through the center of the plot. However, no outliers were seen, and then the normal probability plot of the residuals is valid.

\section{Conclusions}

A flat-plate solar-powered refrigeration system was fabricated to study the relationship between the adsorbent type and its optimal cooling temperature, thus recommending the most appropriate adsorbent for such systems.

From this study it was found that coconut shell's activated carbon is better than palm seed's and charcoal's because it provides the lowest refrigerator temperature among the three adsorbers. From statistical analysis using the general full factorial design it was found that both factors (Adsorbent type and time) had a main effect on both responses under study (the beds temperature and the refrigerator temperature) during day and night cycles respectively. It was also found that coconut shell has the highest mean bed temperature during the day cycle of $77.5^{\circ} \mathrm{C}$, and has the lowest mean temperature during the night cycle with $12.9^{\circ} \mathrm{C}$. There was no significance interaction between the variables of both factors. In addition, it was found from the COP analysis that the coconut shell activated carbon has the highest coefficient of performance of (0.31), followed by the palm seeds with a COP of (0.30), and lastly the charcoal with a COP of $(0.25)$.

\section{REFERENCES}

[1] J. A. Edmonds, D. L. Wuebles and M. J. Scott, "Energy and Radiative Precursor Emissions," International Conference on Alternative Energy Sources, Miami, 14-16 December 1987.

[2] F. Zigler, "Recent Development and Future Prospects of Sorption Heat Pump Systems," International Journal of Thermals, Vol. 38, No. 3, 1999, pp. 191-208. doi:10.1016/S1290-0729(99)80083-0

[3] E. B. Miller "The Development of Silica Gel Refrigeration," Refrigeration Engineering, Vol. 17, No. 4, 1929, pp. 103-108.

[4] G. E. Hulse, "Refroidissement d'un Wagon Frigorifique Marchandise par un Système Adsorptionutilisant le gel de Silice," Revue Generale du Froid, Vol. 10, 1929, p. 281.

[5] D. I. Tchernev, "Solar Energy Cooling with Zéolithes," Proceedings of the NSF/RANN Conference on Energy Conservation, New York, 18-20 February 1974.

[6] R. E. Criptoph, "Performance Limitations of Adsorption Cycles for Solar Cooling," Journal of Solar Energy, Vol. 41, No. 1, 1988, pp. 21-31.

[7] F. Meunier, "Utilisations des Cycles Adsorption Pour la Réfrigération Solaire," Association Franc_Aise pour L'étude et le Développement des Applications de L'énergiesolaire, Vol. 5, 1977, pp. 57-67.

[8] J. J. Guilleminot and F. Meunier "Etude Expérimentale d'une Glacière Solaire Utilisant le Cycle Zéolitheeau," Revue Générale de Thermique, Vol. 239, 1981, pp. 825834.

[9] Ph. Grenier, JJ. Guilleminot, M. Mester, F. Meunier and M. Pons, "Experimental Results on a $12 \mathrm{~m}^{3}$ Solar Powered Cold Store Using the Intermittent Zeolite $13 \mathrm{X}+\mathrm{H}_{2} \mathrm{O}$ Cycle," Proceedings of the ISES Conference, Perth, 1983.

[10] P. Worsoe-Schmidt, "Solar Refrigeration for Developing Countries Using a Solid Adsorption Cycle," Internatioanl Journal of Ambiant Energy, Vol. 4, No. 3, 1983, pp. 115124.

[11] M. Pons and J. J. Guilleminot "Design of an Experimental Solar-Powered Solid Adsorption Ice Maker," Journal of Solar Energy Engineering, Vol. 108, No. 4, 1986, pp. 332-337. doi: $10.1115 / 1.3268115$

[12] D. C. Montgomery and G. C. Runger, "Applied Statistics and Probability for Engineers," 4th Edition, John Wiley \& Sons, Hoboken, 2007. 